\title{
Gastos decorrentes da violência no trânsito e seu reflexo nas despesas da secretaria de saúde em cidade média: o caso de Toledo-PR de 2013 a 2016
}

The proportion of expenses resulting from traffic violence in health department expenses in a medium city: the case of Toledo-PR from 2013 to 2016

\author{
Eder Reli do Couto* \\ Zelimar Soares Bidarra**
}

\begin{abstract}
Resumo: O presente artigo trata de situações atinentes ao trânsito que fazem parte da mobilidade urbana no cotidiano das cidades médias. $O$ texto tem o objetivo de demonstrar os reflexos dos gastos decorrentes de acidentes de trânsito nas despesas da Secretaria da Saúde de Toledo-PR (cidade média) entre os anos de 2013 a 2016, que se originou de uma pesquisa documental, baseada em Relatórios como o SYSBM-RGO do Corpo de Bombeiros, de CID Sintético por Patologia - Ambulatorial e Contábeis da Secretaria Municipal da Saúde, os dados foram abordados de forma quantitativa. Com base na análise dos dados, numa aproximação proporcional, considerando os valores anuais, constatou-se que o custo anual de atendimentos de vítimas de acidentes de trânsito (CID V01-V89) passou de R\$ 32.290,64 em 2013 para R\$ 75.814,92 em 2016, um aumento de 134,79\%, evidenciando como a problemática dos acidentes de trânsito contribuiu para que a cidade de Toledo-PR figurasse no cenário nacional e estadual com uma das que expressaram os maiores índices de violência no trânsito.
\end{abstract}

Palavras-chave: Cidades médias. Mobilidade urbana. Acidentes de trânsito. Saúde pública.

Abstract: This paper addresses the situations related to traffic are part of the daily life of mediumsized cities. This study demonstrates the proportion of expenses resulting from traffic violence in health department expenses in a city of Toledo-PR, between the years 2013 and 2016. To this end, a bibliographical and documentary research was developed, based on Reports such as the SYSBM-RGO of the Fire Department, of Synthetic ICD for Pathology - Ambulatory and Accounting from the City Health Department, the data were approached in a quantitative way. With this, in a proportional approximation, considering the annual values, it was found that the annual cost of care for victims of traffic accidents (ICD V01-V89) went from $R \$ 32,290.64$ in 2013 to $R \$ 75,814.92$ in 2016, an increase of $134.79 \%$, showing how the problem of traffic accidents makes the city of Toledo-PR appear on the national and state scene with one of those that express the highest rates of traffic violence.

Keywords: Medium-sized cities. Urban mobility. Traffic-accidents. Public health.

\footnotetext{
* Mestrando em Desenvolvimento Regional e Agronegócio pela UNIOESTE campus Toledo-Pr.

** Doutorado em Educação pela Universidade Estadual de Campinas e pós-doutorado em Educação pela Universidade Federal do Paraná. Professora Associada da Universidade Estadual do Oeste do Paraná campus Toledo-PR, com atuação no curso de graduação em Serviço Social, no Programa de Mestrado em Serviço Social e no Programa de Mestrado e Doutorado em Desenvolvimento Regional e Agronegócio
} 


\section{Introdução}

A crise urbana, conforme Maricato (2015), expõe a preponderância da questão da terra e revela um de seus importantes problemas - a mobilidade urbana no viés do trânsito. Os desequilíbrios no trânsito manifestam-se de formas diferentes, inclusive como acidentes no trânsito, a depender das condições de circulação e de produção do momento.

Para alguns estudiosos do tema, como SOUZA; MINAYO; MALAQUIAS (2005), os acidentes de trânsito são entendidos como expressões de violência social. Representam um problema de saúde pública, tanto em virtude dos óbitos, quanto em virtude das sequelas geradas às vítimas, considerando-se que, algumas vezes, são irreversíveis.

Este problema de saúde pública requer que o sistema médico-hospitalar permaneça aparelhado para o atendimento das emergências, recaindo sobre o setor da saúde a maior parte do ônus (MELLO JORGE; LATORRE, 1994).

Um dos importantes registros desse ônus encontra-se documentado no estudo publicado pelo Instituto de Pesquisa Econômica Aplicada no ano de 2006, o qual demonstrou que o Brasil, nos últimos trinta anos, tem sido um dos países com elevados índices de acidentes de trânsito. Os gastos atingiram quase "6 bilhões de reais por ano" com vítimas de acidentes de trânsito (IPEA, 2006, p. 26-27).

Esses gastos tiveram várias destinações, dentre elas: os custos dos atendimentos préhospitalares (atendimento da vítima por unidades dotadas de equipamentos especiais, com veículos e profissionais especializados: ambulâncias, bombeiros, médicos, entre outros); os custos dos atendimentos hospitalares (soma dos custos do atendimento médico hospitalar do paciente não internado e do paciente internado na Unidade de Terapia Intensiva e/ou Enfermaria) e os custos pós-hospitalares (a soma dos custos com reabilitação para os casos de sequela temporária ou definitiva, com procedimentos, medicamentos, transporte, equipamentos e outros) (IPEA, 2006).

Considerando esse tipo de cenário que tem se mostrado persistente, desenvolveu-se uma pesquisa ${ }^{1}$ com vistas a responder questões que se reportam à relação entre os temas do espaço urbano, da violência e da saúde. O intuito foi o de demonstrar algumas das consequências dos acidentes de trânsito nas estruturas dos gastos e dos serviços de saúde

\footnotetext{
${ }^{1} \mathrm{O}$ presente artigo contém alguns dados da pesquisa que foi desenvolvida para a dissertação de mestrado de COUTO (2018) apresentada ao Programa de Pós-graduação em Desenvolvimento Regional e Agronegócio/Unioeste/Toledo.
} 
pública. Para tanto, buscou-se conhecer a realidade da cidade de Toledo-PR, que está localizada na região Oeste do estado do Paraná, a qual na última década experimentou um importante processo de crescimento econômico e expansão urbana.

Toledo-PR se caracteriza como cidade média, seja pelo referencial demográfico Castello Branco (2006) e Instituto Brasileiro de Geografia e Estatística (IBGE, 2017), seja pelo atributo das interações espaciais com os municípios de seu entorno e da presença de uma elite econômica empreendedora (CORRÊA, 2007) vinculada às atividades do agronegócio. Tendo em vista atender aos critérios de população, de cidade-polo e de região de influência dentro da rede urbana do Oeste do Paraná, Toledo é reconhecida como cidade média (STAMM, 2005, FERREIRA, 2010, PIACENTI; FERRERA DE LIMA orgs. 2012).

A investigação partiu da seguinte indagação: qual a participação dos gastos com acidentes de trânsito nas despesas da Secretaria Municipal da Saúde de Toledo-PR, entre os anos de 2013 a 2016? A resposta foi construída com base em uma pesquisa documental e na análise quantitativa de dados obtidos em Relatórios, como: o SYSBM-RGO do Corpo de Bombeiros, de CID Sintético por Patologia - Ambulatorial e Relatórios Contábeis da Secretaria Municipal da Saúde.

O objetivo da investigação foi o de demonstrar como que processos econômicos e acelerada expansão urbana em cidade média reproduz um viés da crise de mobilidade, sob a forma da violência no trânsito. Isso sobrecarrega as exíguas estruturas de serviços de saúde em cidades desse porte.

\section{Espaço urbano: problemas de mobilidade e seus reflexos nos acidentes de trânsito e nos custos da saúde pública}

A compreensão de espaço, de acordo com Lefebvre $(1976,1999)$ e Santos (2013), é crucial às ciências e a construção e compreensão do mundo contemporâneo. Ao se questionar “o que é espaço?" deve-se ter em mente que se trata de uma problemática que envolve a consciência, a cultura e a ideologia. No espaço, ocorrem relações econômicas e sociais e se realizam atividades produtivas, científicas, culturais e políticas.

O espaço urbano, de acordo com os autores supracitados, é o ambiente do encontro das coisas e das pessoas e o lugar das trocas. Por suas características de concentração, poli(multi)centricidade, densidade e viabilidade, o espaço urbano contribui historicamente 
para o desenvolvimento capitalista sob a forma de cidades, de diferentes portes, pequena, média e grande.

As reflexões teóricas acerca dos portes e das funções das cidades têm se desenvolvido desde os anos 1960, século XX. Delas resultaram definições, conceitos, sobre como se pode caracterizar as cidades. Dessa forma, a definição de cidade média tem como elemento definidor básico e mais utilizado, o tamanho populacional/demográfico. Outras características passaram a ser consideradas para qualificarem esse tipo a categoria de cidade, tais como: características funcionais, econômicas, grau de urbanização, especialização e diversificação econômica, intensidade das relações interurbanas e com o campo, posição e importância/influência na região, organização do espaço intra-urbano, infraestrutura, índices de qualidade de vida; dentre outros (SOARES, 1999, AMORIM FILHO; SERRA, 2001, CASTELLO BRANCO, 2006, 2007, CORRÊA, 2007, SILVA, 2013).

As cidades médias costumam ser definidas pelo lugar que ocupam na rede urbana e no sistema econômico global, configurando-se como nós articuladores entre grandes metrópoles e cidades menores. No entanto, não há consenso sobre os atributos que definem ou conceituam a cidade média, aqui se faz referência a alguns dos estudos que a tem problematizado, sendo: Pereira (2007, p. 23-25) e Conte (2013, p. 51- 52) que partem da posição da Organização das Nações Unidas (ONU) que considera como cidades médias aquelas que possuem entre 100 mil e três milhões de habitantes, a posição assumida no VII Congresso Ibero Americano de Urbanismo, são aquelas com 20 a 500 mil habitantes e o parâmetro estabelecido pelo Instituto Brasileiro de Geografia e Estatística (IBGE, 2017) que caracteriza as cidades médias como aglomerações urbanas como população entre 100 e 350 mil habitantes. Esse parâmetro costuma ser adotado por vários estudiosos, como em Castello Branco (2006).

No curso do modo de produção capitalista, as cidades médias se constituem como locus de atração de contingentes de migrantes do campo, de pequenas cidades e de pessoas que resolvem sair dos grandes centros em busca de melhores condições de vida. Esse fluxo provoca um crescimento acelerado e faz surgir problemas urbanos e sociais semelhantes aos das grandes cidades (AMORIM FILHO; SERRA, 2001, SOARES, 2006, CASTELLO BRANCO, 2006 e 2007, SPOSITO; ELIAS; SOARES et al., 2007, CONTE, 2013).

No que tange à rede urbana, de acordo com os autores, essas cidades podem desempenhar a função de articuladoras e intermediadoras nos eixos ou corredores de desenvolvimento, constituindo-se em nós da rede urbana que servem a sua área de influência 
como pontos de prestação de serviços. Sob a ótica do mercado consumidor, as cidades médias desempenham o papel de polos para os quais moradores de cidades menores e de áreas rurais se deslocam para consumirem bens e serviços.

Conforme Hildebrand (2001), no contexto brasileiro se evidencia um processo de ocupação do espaço urbano determinado por interesses preponderantemente individuais, privados e especulativos, os quais continuam se sobrepondo aos interesses públicos. $\mathrm{O}$ processo de concretização desses interesses é feito por "agentes sociais da produção do espaço" (CORRÊA, 2011), isto é: um conjunto de atores privados e governamentais que estabelecem o domínio sobre as formas de ocupação territorial e as relações de produção.

Assim, a formação das cidades brasileiras se fez à revelia de processos sistemáticos de planejamento, devido à submissão aos mecanismos de mercado e ao capital imobiliário. Para Maricato (2015) isso resulta num processo de urbanização reproduz a seguinte contradição: por um lado, há a oportunidade de satisfação de necessidades básicas, por outro um ambiente de crescente poluição, violência, criminalidade com restrições à mobilidade e ao exercício do direito à cidade.

A ideia do direito à cidade, como direito coletivo, ressurgiu amparada nos pleitos existentes dos movimentos sociais urbanos que buscaram discutir as configurações da vida urbana. Reivindica-lo é requerer o poder sobre como as cidades são feitas e refeitas. Sua observância é essencial para preservar as funções sociais da cidade com relação ao acesso à terra urbana, à moradia, ao saneamento ambiental, a infraestrutura urbana, ao transporte, ao trabalho e ao lazer com vistas a uma forma de mobilidade que represente 0 desenvolvimento sustentável (HARVEY, 2014).

Para Torres; Ginters (2016) a mobilidade urbana representa a interação entre os deslocamentos de pessoas e bens no espaço urbano, executados tanto por meios motorizados quanto por não-motorizados. O aumento da taxa de motorização, associado ao crescimento demográfico urbano e ao déficit de investimentos em infraestrutura, culminou no agravamento da crise de mobilidade urbana brasileira (PINHEIRO; FRISCHTAK et al., 2015).

O problema de transporte no país se relaciona com a situação da precariedade do sistema de mobilidade, que impele as pessoas a utilizarem o automóvel particular diante da ineficiência do transporte coletivo. Porém, para Vasconcellos (2013), isso se traduz num custo financeiro e no tempo excessivo para deslocamentos, que resulta na exclusão social aos mais vulneráveis. 
Além disso, se temo problema dos acidentes de trânsito, segundo estimativas do IPEA cerca de R\$ 50 bilhões/por ano foram dispendidos em nas consequências desses acidentes. Esse valor englobou o custo referente à perda de produção das vítimas e os gastos com atendimento médico-hospitalar (IPEA apud CARVALHO, 2016, p. 07).

Carvalho (2016, p. 10) apresentou estatísticas do ano de 2013 em que foram registradas 42.266 mortes em Acidentes de Transporte Terrestres no Brasil (ATTs). Para o enfrentamento da questão dos acidentes de trânsito, o poder público deve buscar a interação dos diferentes modais de transporte, relacionando-os às decisões sobre o ordenamento territorial urbano, além de assegurar a eficácia e a efetividade da política pública de mobilidade. É preciso destacar que os gastos gerados pelos acidentes de trânsito atingem a economia, a Previdência Social e o sistema de saúde com altos custos médico-hospitalares (BATISTA; MYRRHA, 2016).

Por acidente de trânsito, entende-se todo evento ocorrido na via pública, inclusive em calçadas, que mesmo não sendo intencional pode ser evitável, decorrente da movimentação de veículos e de pessoas e que causa dano, lesões físicas e emocionais, segundo Ipea (2003, 2006), Souza; Minayo; Malaquias (2005) e Waiselfisz (2013).

Os acidentes de trânsito têm como componentes básicos a pessoa, o veículo, a via e o ambiente (equipamentos, condições climáticas, iluminação, vegetação), o aparato institucional e os aspectos socioambientais (legislação, fiscalização, gestão do tráfego, e regras informais/cultura). O tema dos acidentes de trânsito deve ser abordado como parte de uma complexa interação de fenômenos sociais, psicológicos, físicos e tecnológicos (SOUZA; MINAYO; MALAQUIAS, 2005).

Acidentes e mortes no trânsito, para Kobayashi; Carvalho (2011), se configuram como aspectos da violência urbana e não podem ser tratados somente como um problema de polícia, de legislação ou engenharia, devem ser vistos como uma questão de saúde pública.

Nessa perspectiva, segundo Minayo; Souza (1998) e Minayo (2006), o trânsito expressa uma das formas de violência urbana porque resulta de ações humanas de desrespeito às regras da convivência social e de segurança. Daí serem os acidentes considerados como um grave problema para a saúde pública, dado seu reflexo nos indicadores de morbidade e mortalidade.

Waiselfisz (2013, p. 79) evidenciou, a partir do Sistema de Internações Hospitalares do Sistema Único de Saúde (SIH/SUS) do Ministério da Saúde, que em 2011, as 159.327 internações hospitalares por acidentes de trânsito custaram ao erário $\mathrm{R}$ 210,8 milhões de 
reais. Para apuração dos custos médico-hospitalares pode-se utilizar a mensuração das diárias e taxas hospitalares, o valor dos procedimentos técnicos, os hemoderivados e medicamentos, os exames radiológicos e laboratoriais, dentre outros.

No Brasil os processos de crescimento e de desenvolvimento econômico não foram acompanhados por políticas de desenvolvimento urbano que contemplassem a mobilidade e a segurança no trânsito. Dessa constatação, surgiu o interesse em investigar consequências que resultam de condições precárias ou inadequadas da mobilidade, como os custos relacionados aos acidentes de trânsito em Toledo-PR.

\section{Procedimentos metodológicos}

O estudo teve como base a pesquisa documental com abordagem quantitativa dos dados. A finalidade foi produzir informações a partir de documentos não analisados, cujos dados foram tratados através de técnicas estatísticas.

Segundo Ruschel (2016), IBGE (2017) e Ipardes (2017), Toledo-PR é caracterizada por uma economia agroindustrial, em 2016 apresentou uma população estimada de 133.824 mil habitantes com grau de urbanização de 90,74\%. Em 2014, o PIB per capita do município perfez um valor de $\mathrm{R} \$ 34.463,00$.

De acordo com Detran (2015, p. 40; 2016, p. 40), a frota total do município era de 91.996 mil veículos em 2015, chegando a 95.047 mil em 2016. Esse acréscimo pode ter como explicação o aumento da renda per capita média. Em 2015 e 2016 foram registrados 858 e 773 acidentes em vias municipais, respectivamente (DETRAN, 2016, p. 66).

Comparando a cidade de Toledo-PR com as demais cidades do Paraná em 2013, o município ocupou a 10a posição no Estado com 62 (sessenta e dois) óbitos decorrentes de acidentes de trânsito. Em 2014, ano em que constavam os últimos dados consolidados no portal do SIM do Ministério da Saúde, Toledo-PR registrou 63 (sessenta e três) mortes em virtude de acidentes de trânsito, figurando na 8a colocação no ranking dos 399 municípios do Estado.

Nos anos de 2015 e 2016, de acordo com os Relatórios de CID Sintético, o total de atendimentos ambulatoriais registrados pela Secretaria da Saúde do Município foi de 284.860 e 307.518 mil atendimentos, respectivamente. Nesses mesmos anos, os gastos totais dessa

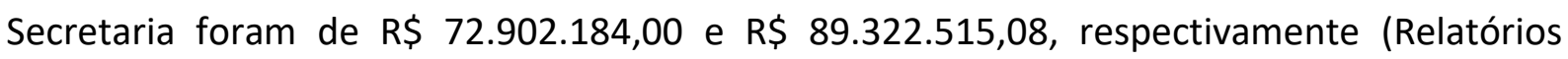
contábeis analisados). 
A opção pela utilização das despesas correntes, e a não inclusão das despesas de capital, deveu-se ao fato de nas despesas correntes se enquadrarem as despesas de custeio e de consumo para manutenção e funcionamento dos serviços públicos, enquanto nas despesas de capital incluem-se a formação ou aquisição de bem de capital, englobando investimentos, inversões financeiras e transferências de capital (BRASIL, 1964).

A investigação teve como fonte os Relatórios dos anos de 2013 a 2016 emitidos pelo sistema de informação, Sistema SCP550, da Prefeitura Municipal de Toledo². Desse Sistema foram extraídos os Relatórios do Demonstrativo da Despesa do Órgão da Secretaria Municipal da Saúde. Outra fonte de dados foram os Relatórios sobre a quantidade de atendimentos das unidades de saúde do município, utilizando o parâmetro da Classificação Internacional de Doenças (CID-10) Sintético por Patologia - Ambulatorial. Essa delimitação do período foi proposta devido à possibilidade de acesso às informações contábeis disponíveis no Sistema Contábil da Prefeitura de Toledo. Somaram-se a estas duas fontes, o Banco de Dados do Corpo de Bombeiros, SYSBM-RGO, do qual se extraiu informações sobre o perfil dos acidentes e das vítimas.

Os Relatórios de CID Sintético por Patologia - Ambulatorial e Demonstrativo da Despesa do Órgão da Secretaria da Saúde foram extraídos entre os dias 20 de março e 24 de abril de 2017. Os dados do banco de dados do Corpo de Bombeiros, SYSBM-RGO, foram obtidos em 01 de setembro de 2017, em planilha do Excel. O tratamento dos dados ocorreu no período de agosto/2017 a junho/2018, sendo feito em planilha do Microsoft Office Excel 365 e software IBM SPSS Statistics 21, licença disponível no curso de Ciências Sociais da Unioeste campus Toledo-PR.

A tabulação dos Relatórios de Demonstrativo de Despesa foi feita por mês, por ano e valor total e a dos Relatórios de CID Sintético por Patologia - Ambulatorial foi feita por mês, por ano e pelo Capítulo XX - Causas externas de morbidade e de mortalidade, separada a subcategoria V01-V89, como consta na categorização dos acidentes de transporte, segundo Datasus (2017). As variáveis desse estudo são quantitativas discretas e contínuas e qualitativa nominal, sendo atendimentos por grupo do CID-10, despesas totais liquidadas e pagas da Secretaria da Saúde, apresentadas numa série temporal.

\footnotetext{
${ }^{2}$ A pesquisa fez uso de dados em arquivo. Procedeu-se a submissão do Projeto ao Comitê de Ética na Pesquisa (CEP) da Unioeste, CAEE n. 74926217.2.0000.0107. O desenvolvimento da investigação se deu com base nos Pareceres n. 2.308.964 e 2.356.597 - CEP/Unioeste.
} 
A cidade de Toledo-PR como cenário do agravamento da violência no trânsito: participação financeira dos acidentes de trânsito nos gastos com a saúde pública

Com os dados obtidos no banco de dados SYSBM-RGO do Corpo de Bombeiros se delineou o perfil das vítimas e a localização dos acidentes de trânsito no município de ToledoPR. Buscou-se demonstrar como as características do espaço urbano e a constituição da cidade impactam na mobilidade urbana, no trânsito e no indivíduo.

A Tabela 1 evidencia que a maioria das vítimas de acidentes de trânsito atendidas pelo Corpo de Bombeiros foi do sexo masculino, $64,33 \%$, o que se coaduna com os estudos do IPEA (2003), de Waiselfisz (2013) e de Carvalho (2016).

Tabela 1 - Vítimas de acidentes de trânsito em Toledo por sexo de 2013 a 2016.

\begin{tabular}{l|cc|cc|cc|cc|cc}
\hline \multirow{2}{*}{ Sexo } & \multicolumn{2}{|c|}{$\mathbf{2 0 1 3}$} & \multicolumn{2}{|c|}{$\mathbf{2 0 1 4}$} & \multicolumn{2}{c|}{$\mathbf{2 0 1 5}$} & \multicolumn{2}{c|}{$\mathbf{2 0 1 6}$} & \multicolumn{2}{c}{ Total } \\
\cline { 2 - 11 } & $\begin{array}{c}\text { Freq. } \\
\text { Absoluta }\end{array}$ & $\begin{array}{c}\text { Freq. } \\
\text { Relativa }\end{array}$ & $\begin{array}{c}\text { Freq. } \\
\text { Absoluta }\end{array}$ & $\begin{array}{c}\text { Freq. } \\
\text { Relativa }\end{array}$ & $\begin{array}{c}\text { Freq. } \\
\text { Absoluta }\end{array}$ & $\begin{array}{c}\text { Freq. } \\
\text { Relativa }\end{array}$ & $\begin{array}{c}\text { Freq. } \\
\text { Absoluta }\end{array}$ & $\begin{array}{c}\text { Freq. } \\
\text { Relativa }\end{array}$ & $\begin{array}{c}\text { Freq. } \\
\text { Absoluta }\end{array}$ & $\begin{array}{c}\text { Freq. } \\
\text { Relativa }\end{array}$ \\
\hline Masculino & 1243 & $63,94 \%$ & 1114 & $62,73 \%$ & 1027 & $65,46 \%$ & 945 & $65,62 \%$ & 4329 & $64,33 \%$ \\
Feminino & 701 & $36,06 \%$ & 662 & $37,27 \%$ & 542 & $34,54 \%$ & 495 & $34,38 \%$ & 2400 & $35,67 \%$ \\
\hline Total & 1944 & $100,00 \%$ & 1776 & $100,00 \%$ & 1569 & $100,00 \%$ & 1440 & $100,00 \%$ & 6729 & $100,00 \%$ \\
\hline
\end{tabular}

Fonte: Pesquisa de campo (2018).

Na Tabela 2 se observa que houve diminuição contínua na quantidade de vítimas nas faixas etárias de 18 (dezoito) a 29 (vinte e nove) anos e de 30 (trinta) a 59 (cinquenta e nove) anos. Na faixa etária de 0 (zero) a 17 (dezessete) anos, crianças e/ou adolescentes, houve diminuição do número absoluto de vítimas em relação a 2013. Todavia entre 2015 e 2016 o número de vítimas aumentou.

Tabela 2 - Vítimas de acidente de trânsito em Toledo por faixa etária de 2013 a 2016.

\begin{tabular}{l|cc|cc|cc|cc|cc}
\hline \multirow{2}{*}{$\begin{array}{l}\text { Faixa de } \\
\text { Idade }\end{array}$} & \multicolumn{2}{|c|}{$\mathbf{2 0 1 3}$} & \multicolumn{2}{|c|}{$\mathbf{2 0 1 4}$} & \multicolumn{2}{c|}{$\mathbf{2 0 1 5}$} & \multicolumn{2}{c|}{$\mathbf{2 0 1 6}$} & \multicolumn{2}{c}{ Total } \\
\cline { 2 - 10 } & $\begin{array}{c}\text { Freq. } \\
\text { Absoluta }\end{array}$ & $\begin{array}{c}\text { Freq. } \\
\text { Relativa }\end{array}$ & $\begin{array}{c}\text { Freq. } \\
\text { Absoluta }\end{array}$ & $\begin{array}{c}\text { Freq. } \\
\text { Relativa }\end{array}$ & $\begin{array}{c}\text { Freq. } \\
\text { Absoluta }\end{array}$ & $\begin{array}{c}\text { Freq. } \\
\text { Relativa }\end{array}$ & $\begin{array}{c}\text { Freq. } \\
\text { Absoluta }\end{array}$ & $\begin{array}{c}\text { Freq. } \\
\text { Relativa }\end{array}$ & $\begin{array}{c}\text { Freq. } \\
\text { Absoluta }\end{array}$ & $\begin{array}{c}\text { Freq. } \\
\text { Relativa }\end{array}$ \\
\hline $\begin{array}{l}\text { De 0 a } 17 \\
\text { anos }\end{array}$ & 233 & $11,98 \%$ & 167 & $9,40 \%$ & 139 & $8,87 \%$ & 143 & $9,93 \%$ & 682 & $10,14 \%$ \\
$\begin{array}{l}\text { De } 18 \text { a } 29 \\
\text { anos }\end{array}$ & 909 & $46,76 \%$ & 832 & $46,85 \%$ & 737 & $46,97 \%$ & 631 & $43,82 \%$ & 3109 & $46,20 \%$ \\
$\begin{array}{l}\text { De 30 a } 59 \\
\text { anos }\end{array}$ & 734 & $37,76 \%$ & 697 & $39,25 \%$ & 625 & $39,83 \%$ & 598 & $41,53 \%$ & 2654 & $39,44 \%$ \\
$\begin{array}{l}\text { De } 60 \text { ou } \\
\text { mais }\end{array}$ & 68 & $3,50 \%$ & 80 & $4,50 \%$ & 68 & $4,33 \%$ & 68 & $4,72 \%$ & 284 & $4,22 \%$ \\
\hline Total & $\mathbf{1 9 4 4}$ & $\mathbf{1 0 0 , 0 0 \%}$ & $\mathbf{1 7 7 6}$ & $\mathbf{1 0 0 , 0 0 \%}$ & $\mathbf{1 5 6 9}$ & $\mathbf{1 0 0 , 0 0 \%}$ & $\mathbf{1 4 4 0}$ & $\mathbf{1 0 0 , 0 0 \%}$ & $\mathbf{6 7 2 9}$ & $\mathbf{1 0 0 , 0 0 \%}$ \\
\hline
\end{tabular}

Fonte: Pesquisa de campo (2018).

Verificou-se que a faixa etária que mais apresentou vítimas de acidentes de trânsito foi a de 18 (dezoito) a 29 (vinte e nove) anos, jovens, totalizando 3109 vítimas, seguida da faixa etária de 30 (trinta) a 59 (cinquenta e nove) anos, adultos, com 2654 vítimas. 
Acompanhando a evolução da participação de cada faixa etária no total de vítimas de acidentes de trânsito conclui-se que o envolvimento de adultos aumentou no período, de $37,76 \%$ em 2013 , para $41,53 \%$ em 2016 , e esse aumento foi mais expressivo se comparado com os jovens de 18 (dezoito) a 29 (vinte e nove) que se manteve estável entre anos de 2013 a 2015, apresentando declínio em 2016. Os idosos, de 60 (sessenta) anos ou mais, percentualmente, aumentaram seu envolvimento em acidentes de trânsito.

Comparando as faixas etárias em que predominaram as vítimas de acidentes de trânsito com a pirâmide etária do Censo Demográfico de 2010 pode-se observar que a faixa etária de 18 (dezoito) a 29 (vinte e nove) anos, jovens, concentrava a maior parte da população. Logo, compreende-se que por haver uma maior população e adicionando os comportamentos de risco de determinado perfil, é possível que haja maiores índices de vítimas de acidentes em determinadas idades.

Sabendo das características pessoais das vítimas, identificou-se na Tabela 3 os principais tipos de lesões sofridas. Constatou-se que das 6729 vítimas de acidentes de trânsito, 352 saíram ilesas, 4630 teve ferimentos leves, 1428 tiveram ferimentos considerados graves, porém sem risco à vida, 241, tiveram ferimentos considerados graves e com risco e 78 faleceram.

Tabela 3 - Vítimas de acidente de trânsito em Toledo por tipo de lesão de 2013 a 2016.

\begin{tabular}{|c|c|c|c|c|c|c|c|c|c|c|}
\hline \multirow[b]{2}{*}{ Tipo de Lesao } & \multicolumn{2}{|c|}{2013} & \multicolumn{2}{|c|}{2014} & \multicolumn{2}{|c|}{2015} & \multicolumn{2}{|c|}{2016} & \multicolumn{2}{|c|}{ Total } \\
\hline & $\begin{array}{c}\text { Freq. } \\
\text { Absoluta }\end{array}$ & $\begin{array}{c}\text { Freq. } \\
\text { Relativa }\end{array}$ & $\begin{array}{c}\text { Freq. } \\
\text { Absoluta }\end{array}$ & $\begin{array}{l}\text { Freq. } \\
\text { Relativa }\end{array}$ & $\begin{array}{c}\text { Freq. } \\
\text { Absoluta }\end{array}$ & $\begin{array}{c}\text { Freq. } \\
\text { Relativa }\end{array}$ & $\begin{array}{c}\text { Freq. } \\
\text { Absoluta }\end{array}$ & $\begin{array}{c}\text { Freq. } \\
\text { Relativa }\end{array}$ & $\begin{array}{c}\text { Freq. } \\
\text { Absoluta }\end{array}$ & $\begin{array}{l}\text { Freq. } \\
\text { Relativa }\end{array}$ \\
\hline Ileso(a) & 82 & $4,22 \%$ & 87 & $4,90 \%$ & 85 & $5,42 \%$ & 98 & $6,81 \%$ & 352 & $5,23 \%$ \\
\hline Ferimentos leves & 1313 & $67,54 \%$ & 1217 & $68,52 \%$ & 1072 & $68,33 \%$ & 1028 & $71,38 \%$ & 4630 & $68,81 \%$ \\
\hline $\begin{array}{l}\text { Ferimentos } \\
\text { considerados } \\
\text { graves sem risco à } \\
\text { vida }\end{array}$ & 451 & $23,20 \%$ & 388 & $21,85 \%$ & 333 & $21,22 \%$ & 256 & $17,78 \%$ & 1428 & $21,22 \%$ \\
\hline $\begin{array}{l}\text { Ferimentos } \\
\text { considerados } \\
\text { graves com risco à } \\
\text { vida }\end{array}$ & 79 & $4,06 \%$ & 59 & $3,32 \%$ & 62 & $3,95 \%$ & 41 & $2,85 \%$ & 241 & $3,58 \%$ \\
\hline Óbito & 19 & $0,98 \%$ & 25 & $1,41 \%$ & 17 & $1,08 \%$ & 17 & $1,18 \%$ & 78 & $1,16 \%$ \\
\hline Total & 1944 & $100,00 \%$ & 1776 & $100,00 \%$ & 1569 & $100,00 \%$ & 1440 & $100,00 \%$ & 6729 & $100,00 \%$ \\
\hline
\end{tabular}

Fonte: Pesquisa de campo (2018).

A maioria dos acidentes teve como tipo de veículo a motocicleta, $57,24 \%$, seguido do automóvel, 23,20\%. Adicionando a bicicleta, com 13,92\%, atingiu-se o percentual de $94,36 \%$ das vítimas. 
A maior incidência de acidentes envolvendo automóveis e motocicletas se deve a quantidade desses tipos de veículos na composição da frota municipal. Segundo Detran (2013 p. 31; 2014 p. 31; 2015 p. 31; 2016 p. 31), no período, a frota municipal foi acrescida em 11.354 veículos, passando de 83.693 veículos em 2013, para 88.364 em 2014, 91.996 em 2015 e 95.047 em 2016.

Do total em 2013, 44.487 (53,15\%) eram automóveis e 14.847 (17,74\%) eram motocicletas. Em 2014, 47.122 (53,33\%) eram automóveis e 15.066 (17,05\%) eram motocicletas. Em 2015, os automóveis totalizaram 49.110 (53,38\%) e as motocicletas 15.316 (16,65\%). Em 2016, 50.551 (53,18\%) eram automóveis e 15.538 (16,35\%) eram motocicletas. Houve uma sutil variação nos percentuais.

Apesar de a quantidade de motocicletas ser inferior foram elas que totalizaram o maior número de vítimas de acidentes de trânsito. Depreende-se que a intensificação dos deslocamentos em um ritmo maior que a expansão geográfica do espaço urbano, acrescido do aumento populacional de 5.376 habitantes no período e, consequentemente, o aumento da densidade demográfica promoveu a concentração geográfica. Isso resultou numa maior disputa e na ampliação dos conflitos pelo uso e a ocupação do espaço, principalmente no curto prazo.

$\mathrm{Na}$ Tabela 4 encontram-se detalhados os destinos dados às vítimas, após serem executados os primeiros socorros pelo Corpo de Bombeiros. A maioria foi encaminhada para o Hospital Bom Jesus (que na atualidade constitui-se como associação beneficente privada sem fins lucrativos que compõe a rede de saúde do município, mas cuja gestão não é de responsabilidade do poder público municipal. Esse Hospital recebe recursos do SUS e de outras fontes públicas via Consórcio Intermunicipal de Saúde. Mas, há de se destacar o aumento do número de vítimas encaminhadas à Unidade de Pronto Atendimento - UPA, tornando-se o segundo maior destino. Observando a série temporal percebeu-se uma gradual inversão da relação dos atendimentos das vítimas entre o Hospital Bom Jesus e a UPA.

Tabela 4 - Destinação das vítimas de acidentes de trânsito em Toledo de 2013 a 2016.

\begin{tabular}{|c|c|c|c|c|c|c|c|c|c|c|}
\hline \multirow[b]{2}{*}{ Destinação } & \multicolumn{2}{|c|}{2013} & \multicolumn{2}{|c|}{2014} & \multicolumn{2}{|c|}{2015} & \multicolumn{2}{|c|}{2016} & \multicolumn{2}{|c|}{ Total } \\
\hline & $\begin{array}{c}\text { Freq. } \\
\text { Absoluta }\end{array}$ & $\begin{array}{c}\text { Freq. } \\
\text { Relativa }\end{array}$ & $\begin{array}{c}\text { Freq. } \\
\text { Absoluta }\end{array}$ & $\begin{array}{c}\text { Freq. } \\
\text { Relativa }\end{array}$ & $\begin{array}{c}\text { Freq. } \\
\text { Absoluta }\end{array}$ & $\begin{array}{c}\text { Freq. } \\
\text { Relativa }\end{array}$ & $\begin{array}{c}\text { Freq. } \\
\text { Absoluta }\end{array}$ & $\begin{array}{c}\text { Freq. } \\
\text { Relativa }\end{array}$ & $\begin{array}{c}\text { Freq. } \\
\text { Absoluta }\end{array}$ & $\begin{array}{c}\text { Freq. } \\
\text { Relativa }\end{array}$ \\
\hline $\begin{array}{l}\text { HCO - Centro } \\
\text { Hospitalar do } \\
\text { Oeste }\end{array}$ & 28 & $1,44 \%$ & 1 & $0,06 \%$ & 3 & $0,19 \%$ & 1 & $0,07 \%$ & 33 & $0,49 \%$ \\
\hline
\end{tabular}




\begin{tabular}{|c|c|c|c|c|c|c|c|c|c|c|}
\hline \multirow{2}{*}{ Destinação } & \multicolumn{2}{|c|}{2013} & \multicolumn{2}{|c|}{2014} & \multicolumn{2}{|c|}{2015} & \multicolumn{2}{|c|}{2016} & \multicolumn{2}{|c|}{ Total } \\
\hline & $\begin{array}{c}\text { Freq. } \\
\text { Absoluta }\end{array}$ & $\begin{array}{c}\text { Freq. } \\
\text { Relativa }\end{array}$ & $\begin{array}{c}\text { Freq. } \\
\text { Absoluta }\end{array}$ & $\begin{array}{c}\text { Freq. } \\
\text { Relativa }\end{array}$ & $\begin{array}{c}\text { Freq. } \\
\text { Absoluta }\end{array}$ & $\begin{array}{l}\text { Freq. } \\
\text { Relativa }\end{array}$ & $\begin{array}{c}\text { Freq. } \\
\text { Absoluta }\end{array}$ & $\begin{array}{c}\text { Freq. } \\
\text { Relativa }\end{array}$ & $\begin{array}{c}\text { Freq. } \\
\text { Absoluta }\end{array}$ & $\begin{array}{c}\text { Freq. } \\
\text { Relativa }\end{array}$ \\
\hline $\begin{array}{l}\text { Hoesp - } \\
\text { Associação } \\
\text { Beneficente de } \\
\text { Saúde do Oeste do } \\
\text { Paraná / Bom } \\
\text { Jesus }\end{array}$ & 1018 & $52,36 \%$ & 954 & $53,71 \%$ & 480 & $30,59 \%$ & 166 & $11,53 \%$ & 2618 & $38,91 \%$ \\
\hline $\begin{array}{l}\text { NIS }{ }^{3} \text { - Núcleo } \\
\text { Integrado de } \\
\text { Saúde Dr. Milton } \\
\text { Jorge Nunes / Mini } \\
\text { Hospital }\end{array}$ & 629 & $32,36 \%$ & 547 & $30,80 \%$ & 43 & $2,74 \%$ & 0 & $0,00 \%$ & 1219 & $18,12 \%$ \\
\hline $\begin{array}{l}\text { UPA - Unidade De } \\
\text { Pronto } \\
\text { Atendimento DR. } \\
\text { José Ivo Alves Da } \\
\text { Rocha. }\end{array}$ & 6 & $0,31 \%$ & 3 & $0,17 \%$ & 744 & $47,42 \%$ & 941 & $65,35 \%$ & 1694 & $25,17 \%$ \\
\hline $\begin{array}{l}\text { IML - Instituto } \\
\text { Médico Legal }\end{array}$ & 14 & $0,72 \%$ & 18 & $1,01 \%$ & 13 & $0,83 \%$ & 15 & $1,04 \%$ & 60 & $0,89 \%$ \\
\hline $\begin{array}{l}\text { Liberada no local / } \\
\text { Recusou } \\
\text { encaminhamento }\end{array}$ & 236 & $12,14 \%$ & 244 & $13,74 \%$ & 281 & $17,91 \%$ & 307 & $21,32 \%$ & 1068 & $15,87 \%$ \\
\hline Outros & 13 & $0,67 \%$ & 9 & $0,51 \%$ & 5 & $0,32 \%$ & 10 & $0,69 \%$ & 37 & $0,55 \%$ \\
\hline Total & 1944 & $100,00 \%$ & 1776 & $100,00 \%$ & 1569 & $100,00 \%$ & 1440 & $100,00 \%$ & 6729 & $100,00 \%$ \\
\hline
\end{tabular}

Fonte: Pesquisa de campo (2018).

As unidades de saúde de responsabilidade do poder público municipal que receberam vítimas de acidentes de trânsito foram a UPA e o NIS/Mini Hospital, que somadas totalizaram 2913 atendimentos de vítimas de acidentes de trânsito.

As categorias Liberada no local/Recusou encaminhamento e a IML foram analisadas comparativamente com os dados da Tabela 3. Observou-se que as vítimas liberadas no local aumentaram de 2013 para 2016, totalizando 1068 vítimas.

Comparando esse dado com o número de vítimas por tipo de lesão, depreende-se que do total de vítimas liberadas ou que recusam atendimento uma parte pode ter tido ferimentos, visto que as vítimas ilesas no período totalizaram 352. Houve vítimas que mesmo feridas recusaram o encaminhamento inicial, contudo isso não significa que não tenham necessitado atendimento posterior.

\footnotetext{
${ }^{3}$ Obs.: Os encaminhamentos feitos ao NIS/Mini Hospital que zeraram em 2016, em razão de seu fechamento temporário.
} 
Identificadas as características das vítimas procurou-se demonstrar como esses acidentes se distribuíram no espaço urbano de Toledo-PR. Com 1529 vítimas contabilizadas, o Centro foi o bairro com maior incidência, corroborando Ruschel (2016).

Cabe fazer a ressalva de que para além da área central da zona urbana, dadas as características do município de Toledo-PR, o segundo lugar geral em número de vítimas de acidentes de trânsito configurou-se na Zona Rural, com 479 vítimas, que se comparadas ao total de vítimas registradas no Centro, correspondeu a 31,33\%, ou seja, aproximadamente 1/3 do total de vítimas registradas.

A concentração espacial das vítimas de acidentes de trânsito no Centro da cidade se relaciona com as características de oferta de bens e serviços, a convergência das atividades financeiras, econômicas e a centralidade das rotas de deslocamento, questões também apontadas por Ruschel (2016). Fato a ser destacado é que o bairro periférico nominado como Vila Pioneiro (aquele com maior população pelo registro do Censo2010) ocupou o terceiro lugar no registro de vítimas de acidentes, ainda que nele se tenha um elevado fluxo de pessoas e veículos.

A Zona Rural de Toledo (composta por distritos e vilas) faz uma coesa intersecção com a área urbana. Apesar da baixa densidade demográfica ficou em segundo lugar no registro de vítimas de acidentes de trânsito. Isso pode estar relacionado à trafegabilidade das estradas rurais, em sua maioria, pavimentadas, mas sem acostamento, e no período noturno, por não haver iluminação pública, a visibilidade é afetada.

Na Zona Rural se concentra a produção agropecuária fornecedora de matéria-prima para os estabelecimentos agroindustriais localizados nas franjas da área urbana, essa interação da atividade econômica motiva um cotidiano de intenso fluxo de deslocamentos rural-urbano.

O número total de atendimentos das unidades de saúde do município de Toledo-PR aumentou de 294.063 atendimentos para 364.936. Em relação ao Capítulo do CID que engloba os acidentes de trânsito, Capítulo XX CID V01-Y98, causas externas de morbidade e de mortalidade, apurou-se um total de 6.792 atendimentos.

Em valores absolutos a quantidade de atendimentos classificados nesse Capítulo de CID aumentou no decorrer do período analisado. Extraindo do Capítulo XX CID V01-Y98, causas externas de morbidade e de mortalidade, somente os atendimentos relacionados com os acidentes de trânsito, CID V01-V89, procurou-se demonstrar a quantidade de vítimas de acidentes de trânsito na cidade de Toledo-PR. 
Constatou-se que ocorreram 230 (duzentos e trinta) atendimentos nas unidades de saúde em 2013, 280 (duzentos e oitenta) atendimentos em 2014, 466 (quatrocentos e sessenta e seis) atendimentos em 2015 e 651 (seiscentos e cinquenta e um) atendimentos em 2016, totalizando 1.627 atendimentos no período.

Mesmo havendo a possibilidade, de liberação e/ou recusa de encaminhamento, percebeu-se uma discrepância entre o número de vítimas registradas pelo Corpo de Bombeiros e as encaminhadas exclusivamente para as unidades municipais (NIS/Mini Hospital e UPA) que totalizaram 2.913 vítimas.

A Tabela 5 registrou que o total de atendimentos de vítimas de acidentes de trânsito nas unidades de saúde municipais foi de 1.627. Dessa forma, se tem uma diferença de 1.286 vítimas de acidentes encaminhadas às referidas unidades e que não foram contabilizadas pelo sistema de atendimento no local do acidente. O que dificulta a precisão dos sistemas de dados dos órgãos oficiais brasileiros.

Tabela 5 - Número de vítimas de acidentes de trânsito atendidas nas unidades de saúde de Toledo de 2013 a 2016 (CID V01-V89).

\begin{tabular}{cccc}
\hline Ano & Freq. Absoluta & Freq. Relativa & F. Rel. Acumulada \\
\hline 2013 & 230 & $14,14 \%$ & $14,14 \%$ \\
2014 & 280 & $17,21 \%$ & $31,35 \%$ \\
2015 & 466 & $28,64 \%$ & $59,99 \%$ \\
2016 & 651 & $40,01 \%$ & $100,00 \%$ \\
\hline Total & $\mathbf{1 6 2 7}$ & $\mathbf{1 0 0 , 0 0 \%}$ & - \\
\hline
\end{tabular}

Fonte: Pesquisa de campo (2018).

A divergência entre os números dos bancos de dados consultados mostra que há atendimentos que não adentraram a classificação como atendimentos de vítimas de acidentes de trânsito, esses podem estar "ocultados" em outras CID's que apresentam maior número de atendimentos.

Acompanhando a evolução das despesas totais liquidadas da Secretaria Municipal da Saúde de Toledo, entre os anos de 2013 a 2016, percebeu-se um aumento de 72,04\% ao final do período. Esse aumento ocorreu gradualmente, a cada ano, totalizando $\mathrm{R} \$ \mathbf{2 8 2 . 4 8 8 . 6 1 2 , 6 4}$ (duzentos e oitenta e dois milhões, quatrocentos e oitenta e oito mil, seiscentos e dois reais e

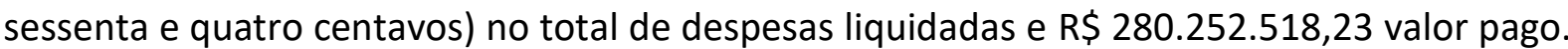
Essa diferença se deve à inscrição de valores em restos a pagar no final de cada exercício.

Selecionando dentre as despesas totais liquidadas, em cada ano, aquelas classificadas como despesas correntes, relacionadas aos gastos operacionais com a manutenção e 
prestação dos serviços públicos obteve-se a cifra de $\mathrm{R} \$$ 138.841.348,30 (cento e trinta e oito milhões, oitocentos e quarenta e um mil, trezentos e quarenta e oito reais e trinta centavos) no total do quadriênio analisado, que representou $49,15 \%$ do total de despesas liquidadas no período. O valor total das despesas liquidadas das contas de despesa analisadas, Tabela 6, oscilou no período.

Tabela 6 - Contas de Despesas Analisadas e Valor das Despesas liquidadas da Secretaria Municipal de Saúde de Toledo de 2013 a 2016

\begin{tabular}{ccccc}
\hline Ano & Valor (R\$) & Freq. Relativa & F. Relat. Acumulada \\
\hline 2013 & R\$ & $41.284 .703,94$ & $29,74 \%$ & $29,74 \%$ \\
2014 & R\$ & $22.038 .701,38$ & $15,87 \%$ & $45,61 \%$ \\
2015 & R\$ & $33.017 .798,32$ & $23,78 \%$ & $69,39 \%$ \\
2016 & R $\$$ & $42.500 .144,66$ & $30,61 \%$ & $100,00 \%$ \\
\hline Total & R\$ & $\mathbf{1 3 8 . 8 4 1 . 3 4 8 , 3 0}$ & $\mathbf{1 0 0 , 0 0 \%}$ & - \\
\hline Fon
\end{tabular}

O motivo do declínio no valor das despesas liquidadas analisadas de 2013 para 2014 foi a extinção da conta Gerenciamento de Recursos Humanos - Fundo Municipal de Saúde. A partir de 2015 os valores das despesas aumentam e isso se deveu as despesas vinculadas a Manutenção Unidade Pronto Atendimento (UPA) e processo de criação do Hospital Regional, que em 2013 era 0 (zero) e em 2016 apresentou um total de $\mathrm{R} \$ 25.526 .762,04$. Isto é: 18,39\% do total de despesas liquidadas no período.

Fazendo a comparação entre os valores totais das despesas liquidadas das contas analisadas da Secretaria da Saúde, entre 2013 (R\$ 41.284.703,94) e 2016 (R\$ 42.500.144,66) para com o número de atendimentos realizados nas unidades de saúde do município entre 2013 (294.063) e 2016 (364.936) para com o total de atendimentos somente do CID V01-V89, acidentes de trânsito, entre 2013 (230) e 2016 (651) percebeu-se que a variação apresentada no número total de atendimentos e no número de atendimentos de vítimas de acidentes de trânsito divergiram das variáveis das despesas liquidadas.

Desta feita, com o Gráfico 1, por meio da análise da dispersão, observando outliers viu-se que o maior número de atendimentos de vítimas de acidentes de trânsito (eixo horizontal) foi 73 , em março de 2015, mês que contabilizou $\mathrm{R} \$ 2.906 .633,76$ de despesas liquidadas. O maior valor de despesa liquidada (eixo vertical) foi $\mathrm{R} \$ 5.938 .309,20$ em novembro de 2013, mês em que foram registrados 11 (onze) atendimentos de vítimas de acidentes de trânsito. A maior concentração de casos, 19 dos 48, situou-se entre 20 e 40 
atendimentos por mês e entre $\mathrm{R} \$ 2$ milhões e $\mathrm{R} \$ \mathbf{4}$ milhões de reais de despesas liquidadas por mês.

Gráfico 1 - Análise da Dispersão dos valores das despesas liquidadas em relação ao número de atendimentos de vítimas de acidentes de trânsito.

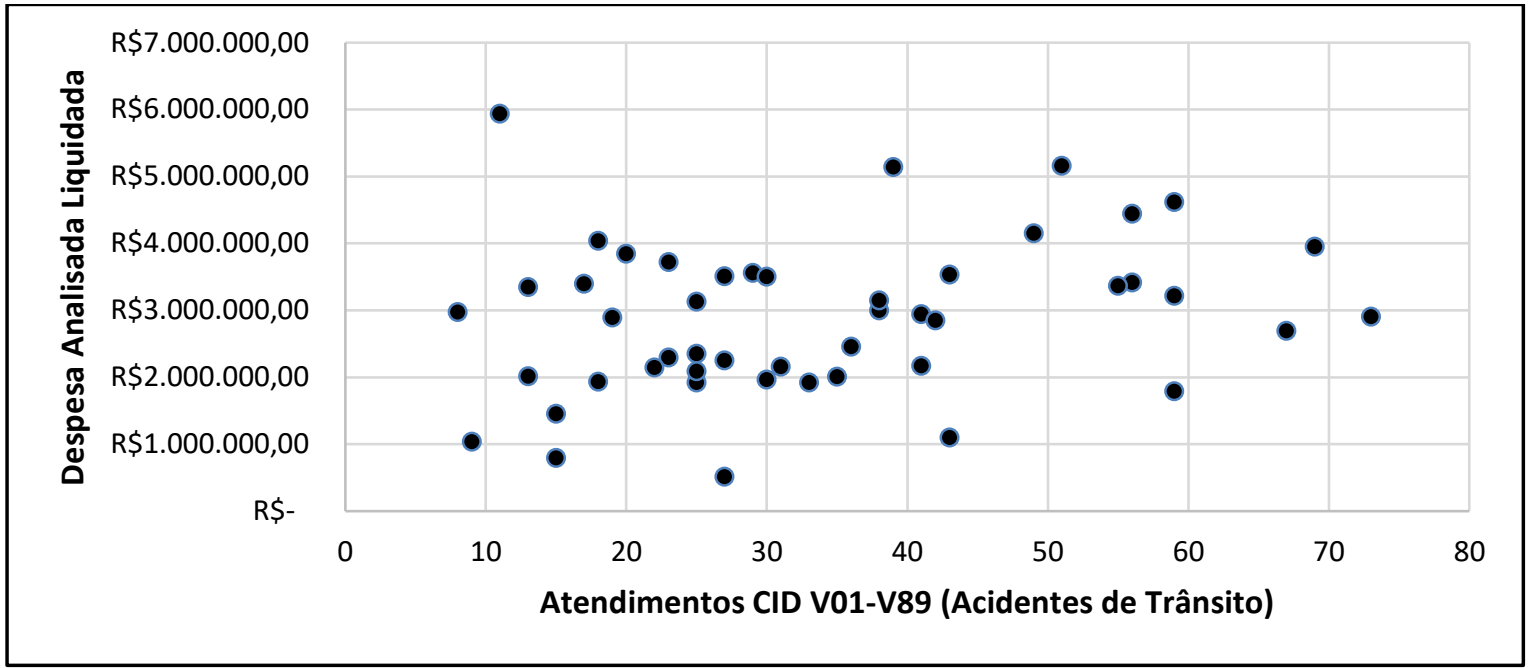

Fonte: Pesquisa de campo (2018).

Para apurar a participação dos acidentes de trânsito nas despesas da saúde pública de Toledo-PR estabeleceu-se uma aproximação por meio da proporcionalidade dos valores, sabendo que o total de despesas liquidadas no período, de janeiro de 2013 a dezembro de 2016, das contas de despesas analisadas, foi de $\mathrm{R} \$ 1$ 138.841.348,30 (cento e trinta e oito milhões, oitocentos e quarenta e um mil, trezentos e quarenta e oito reais e trinta centavos) e que o total de atendimentos nas unidades de saúde do município no período, jan/2013 a dez/2016, foi de 1.373 .538 (um milhão trezentos e setenta e três mil e quinhentos e trinta e oito) atendimentos, chegou-se a um custo aproximado de $\mathrm{R} \$ 101,08$ (cento e um reais e oito centavos) por atendimento no período.

Considerando que o total de atendimentos das unidades de saúde do município registrados sob os CID V01-V89, acidentes de trânsito, entre janeiro de 2013 e dezembro de 2016 foi de 1.627 (mil seiscentos e vinte e sete) atendimentos, calculou-se um custo de R\$ $164.462,05$ (cento e sessenta e quatro mil, quatrocentos e sessenta e dois reais e cinco centavos) com o atendimento de vítimas de acidentes de trânsito, um tipo de despesa de caráter evitável. Todavia, esse custo pode ser maior se considerados aqueles custos considerados como intangíveis.

Numa aproximação proporcional, considerando os valores anuais, constatou-se, conforme Tabela 7, que o custo anual de atendimentos de vítimas de acidentes de trânsito 
(CID V01-V89) passou de $\mathrm{R} \$ 32.290,64$ em 2013 para $\mathrm{R} \$$ 75.814,92 em 2016, um aumento de 134,79\% aproximadamente. A participação percentual desses custos em relação às despesas liquidadas em cada ano passa de 0,0782\% em 2013 para 0,1784\% em 2016, demonstrando uma tendência de crescimento do custo dos atendimentos das vítimas de acidentes de trânsito em relação ao valor total das despesas liquidadas por ano.

Tabela 7 - Custo dos Atendimentos das Vítimas de Acidentes de Trânsito por Ano

\begin{tabular}{ccc}
\hline Ano & Custo Total dos Atendimentos & $\begin{array}{c}\text { Participação Percentual em Relação as Despesas } \\
\text { Liquidadas }\end{array}$ \\
\hline 2013 & $\mathrm{R} \$ 32.290,64$ & $0,0782 \%$ \\
2014 & $\mathrm{R} \$ 17.020,65$ & $0,0772 \%$ \\
2015 & $\mathrm{R} \$ 43.712,43$ & $0,1324 \%$ \\
2016 & $\mathrm{R} \$ 75.814,92$ & $0,1794 \%$ \\
\hline
\end{tabular}

Fonte: Elaborado pelo autor (2018).

Por fim, o valor total estimado de custo de atendimento de vítimas de acidentes de trânsito, R\$ 164.462,05; equivaleu nas contas da Secretaria Municipal da Saúde a, aproximadamente, 1 (um) ano do Programa Mais Médicos, dados os valores dos anos 2015 e 2016 dessa conta de despesa, $\mathrm{R} \$ 154.337,38$ e $\mathrm{R} \$ 145.802,32$, respectivamente. Assim, tornou-se possível demonstrar o comprometimento de contas públicas numa cidade média com um tipo de fenômeno, violência no trânsito, que pode ser evitado e mitigado se o escopo da atuação do poder público envidar maiores esforços para construir condições de mobilidade que se coadunem com a premissa do respeito ao direito à cidade.

\section{Considerações finais}

Contextualizadas as relações existentes entre a urbanização na sociedade brasileira e os problemas concernentes à violência no trânsito, em que aspectos da deficiente mobilidade influenciam diretamente no bem-estar e na saúde dos habitantes e se refletem, também, em prejuízos tangíveis, como os custos com os acidentes de trânsito.

Para além disso, há o custo de vidas perdidas em acidentes de trânsito, que resultam de inadequações na condução de políticas de mobilidade urbana. Na cidade de Toledo-PR essa problemática a colocou entre as cidades com maiores índices de mortalidade no trânsito no estado do Paraná (WAISELFISZ, 2013).

Esse fato repercute na saúde pública, principalmente na atenção hospitalar, que passou a ter gastos crescentes no decorrer dos últimos anos. Contudo, não se conhecia, até 
então, quais os reflexos das enfermidades decorrentes dos acidentes no aumento desses gastos. Apurou-se que para a Secretaria Municipal da Saúde de Toledo-Pr esse custo, no período de 2013 a 2016, foi de $\mathrm{R} \$ 164.462,05$.

Apesar de os dados apurados apontarem para uma diminuição do número de vítimas de acidentes de trânsito, cabe destacar a importância de o poder público repensar a organização e a ocupação do espaço urbano, promovendo e priorizando o transporte público, dando-Ihe capilaridade e regularidade. E, concomitante, melhorar a trafegabilidade e a fluidez para os demais meios de transporte, motos, carros e caminhões, esses últimos com regiões delimitadas em que possam circular.

Como sugestão para estudos posteriores, é preciso considerar a apuração das despesas as suas naturezas, ou seja, filtrar os relatórios de despesas selecionando os valores segundo o código da natureza de despesa sintética e até analítica.

\section{Referências}

AMORIM FILHO, O.; SERRA, R. V. Evolução e perspectivas do papel das cidades médias no planejamento urbano e regional. In: ANDRADE, T. A.; SERRA, R. V. (orgs). Cidades médias brasileiras. Rio de Janeiro: IPEA. 2001. p. 01-34. Disponível em:

<http://www.ipea.gov.br/portal/index.php?option=com_content\&view=article\&id=5397>. Acesso em: 12 de jul. 2017.

BATISTA, M. E.; MYRRHA, L. J. D. Uma análise dos custos gerados pelos acidentes de trânsito no Brasil ao Sistema Único de Saúde e o seu financiamento pelo seguro DPVAT (2005-2011). Revista Debate Econômico, v. 4, n. 1, jan-jun, p. 78-92, 2016. Disponível em: https:// revistas/index.php/revistadebateeconomico/article/view/417. Acesso: 03 de mai. 2017.

BRASIL. Lei no 4.320, de 17 de março de 1964. Estatui normas gerais de direito financeiro para elaboração e controle dos orçamentos e balanços da União, dos Estados, dos Municípios e do Distrito Federal. Brasília, DF: Diário Oficial da União; Brasil, 23 de mar. de 1964. Disponível em: <http://www.planalto.gov.br/ccivil_03/Leis//4320.htm. Acesso: 08 de jun. 2018.

Lei no 12.587, de 3 de janeiro de 2012. Institui as diretrizes da Política Nacional de Mobilidade Urbana; revoga dispositivos dos Decretos-Leis no 3.326, de 3 de junho de 1941, e 5.405, de 13 de abril de 1943, da Consolidação das Leis do Trabalho (CLT), aprovada pelo Decreto-Lei $n=5.452$, de 10 de maio de 1943, e das Leis no 5.917, de 10 de setembro de 1973, e 6.261, de 14 de novembro de 1975; e dá outras providências. Diário Oficial da União, Brasil, 04 de jan. de 2012. Disponível: <http://www.planalto.gov.br/ccivil_03/_ato20112014/2012/lei/l12587.htm>. Acesso em: $01 \mathrm{de} \mathrm{fev.} 2017$.

CARVALHO, C. H. R. de. Mortes por acidentes de transporte terrestre no Brasil: análise dos sistemas de informação do ministério da saúde. Texto para discussão. Brasília/Rio de Janeiro: Ipea, 2016. Disponível: 
<http://www.ipea.gov.br/portal/images/stories/PDFs/TDs/td_a2212.pdf>. Acesso em: 25 de jul. 2016.

CASTELLO BRANCO, M. L. Cidades médias no Brasil. In: SPÓSITO, E. S.; SPOSITO, M. E. B.; SOBARZO, O. (org.). Cidades médias: produção do espaço. São Paulo: Expressão Popular, 2006.

Algumas considerações sobre a identificação de cidades médias. In: SPOSITO, M. E.

B. (org.). Cidades médias: espaços em transição. São Paulo: Expressão Popular, 2007.

CONTE, C. H. Cidades médias: discutindo o tema. Sociedade e Território, Natal, v. 25, n. 1, p. 45-61, jan./jun., 2013. Disponível:

<https://periodicos.ufrn.br/sociedadeeterritorio/article/viewFile/3516/2829>. Acesso: 12 de jul. 2017.

CORRÊA, R. L. Construindo o conceito de cidade média. In: SPOSITO, M. E. B. (org.). Cidades médias: espaços em transição. 1. ed. São Paulo: Expressão Popular, 2007.

As pequenas cidades na confluência do urbano e do rural. GEOUSP - Espaço e Tempo. São Paulo, no 30, pp. 05 - 12, 2011. Disponível em:

https://www.google.com/search?q=C\%C3\%94RREA\%2C+Roberto+Lobato+agentes+produtor es+do+espa\%C3\%A7o+urbano\&oq=C\%C3\%94RREA\%2C+Roberto+Lobato+agentes+produtor es+do+espa\%C3\%A7o+urbano\&aqs=chrome..69i57j33i22i29i30l2.8794j0j15\&sourceid=chro me\&ie=UTF-8. Acesso: 29 de abr. 2021.

COUTO, E. R. de. Participação financeira dos acidentes de trânsito nas despesas da Secretaria Municipal da Saúde do município de Toledo-Pr, entre os anos de 2013 a 2016. Dissertação (mestrado). Programa de Pós-graduação em Desenvolvimento Regional e Agronegócio. Universidade Estadual do Oeste do Paraná (Unioeste). 2018.

DATASUS - BANCO DE DADOS DO SISTEMA ÚNICO DE SAÚDE. São Paulo: Centro Colaborador da OMS para a Classificação de Doenças em Português, 2017. Disponível em: <http://www.datasus.gov.br/cid10/V2008/WebHelp/v01_y98.htm>. Acesso em: 26 de abr. de 2017.

DETRAN - DEPARTAMENTO DE TRÂNSITO DO PARANÁ. Anuário estatístico 2013. [s. I., s. n.], 2013. Disponível: <http://www.detran.pr.gov.br/modules/catasg/servicosdetalhes.php?tema=detran\&id=477>. Acesso em: 01 de mar. 2017.

Anuário estatístico 2014. [s. I., s. n.], 2014. Disponível em: <http://www.detran.pr.gov.br/modules/catasg/servicosdetalhes.php?tema=detran\&id=477>. Acesso em: 01 de mar. 2017.

Anuário estatístico 2015. [s. I., s. n.], 2015. Disponível em: <http://www.detran.pr.gov.br/modules/catasg/servicosdetalhes.php?tema=detran\&id=477>. Acesso em: 01 de mar. 2017.

Anuário estatístico 2016. [s. I., s. n.], 2016. Disponível em: <http://www.detran.pr.gov.br/modules/catasg/servicosdetalhes.php?tema=detran\&id=477>. Acesso em: 23 de jul. 2018. 
FERREIRA, S. C. Rede urbana, cidades de porte médio e cidades médias: estudos sobre Guarapuava no estado do Paraná. Tese (doutorado) - Universidade Estadual Paulista (Unesp), Faculdade de Ciências e Tecnologia. Presidente Prudente, 2010.

HARVEY, D. Cidades rebeldes: do direito à cidade à revolução urbana. São Paulo: Martins Fontes, 2014.

HILDEBRAND, A. R. (org.). Nova lei da reforma urbana e o estatuto da cidade. São Paulo: Editora de Direito, 2001.

IBGE - INSTITUTO BRASILEIRO DE GEOGRAFIA E ESTATÍ́STICA. Censo demográfico 2010, Brasil em síntese, Cidades. [s. I., s. n.], 2017. Disponível:

<http://cidades.ibge.gov.br/v4/brasil/pr/toledo/panorama>. Acesso em: 07 de mai. 2017.

IPARDES - INSTITUTO PARANAENSE DE DESENVOLVIMENTO ECONÔMICO E SOCIAL.

Cadernos estatístico município de Toledo. [s. I., s. n.], 2017. Disponível:

<http://www.ipardes.gov.br/cadernos/MontaCadPdf1.php?Municipio=85900\&btOk=ok>.

Acesso em: 07 de mai. 2017.

IPEA - INSTITUTO DE PESQUISA ECONÔMICA APLICADA. Impactos sociais e econômicos dos acidentes de trânsito nas aglomerações urbanas brasileiras: relatório executivo. Brasília: IPEA/ANTP, 2003. Disponível em: <http://criancasegura.org.br/wpcontent/uploads/2016/08/11.pdf>. Acesso em: 28 abr. 2016.

Impactos sociais e econômicos dos acidentes de trânsito nas rodovias brasileiras. Brasília: IPEA/DENATRAN/ANTP, 2006. Disponível em: <http://docplayer.com.br/5856923Impactos-sociais-e-economicos-dos-acidentes-de-transito-nas-rodovias-brasileiras-relatoriofinal-ipea-denatran-dezembro-2006.html>. Acesso em: 28 abr. 2016.

KOBAYASHI, C. R.; CARVALHO, M. S. Violência urbana: acidentes de trânsito envolvendo motociclistas na cidade de Londrina (PR). Revista Geografia. Londrina, v. 20, n. 3, p. 171-190, set./dez., 2011. Disponível em:

<http://www.uel.br/revistas/uel/index.php/geografia/article/view/8603>. Acesso: 01 de mar. 2017.

LEFEBVRE, H. Espacio y política: el derecho a la ciudad, II. Barcelona: Península, 1976.

A revolução urbana. Belo Horizonte: UFMG, 1999.

MARICATO, E. Para entender a crise urbana. 1. ed. São Paulo: Expressão Popular, 2015.

MELLO JORGE, M. H. P. de; LATORRE, M. R. D. O. Acidentes de trânsito no Brasil: dados e tendências. Cadastro Saúde Pública, Rio de Janeiro, v. 10: p. 9-44, 1994. Disponível: <http://www.scielo.br/pdf/csp/v10s1/v10supl1a03.pdf>. Acesso em: 28 de abr. 2016.

MINAYO, M. C. de S. Violência e saúde. Rio de Janeiro: Editora FIOCRUZ, 2006.

MINAYO, M. C. de S.; SOUZA, E. R. de. Violência e saúde como um campo interdisciplinar e de ação coletiva. História, Ciência, Saúde. Manguinhos, v. 3, p. 513-531, nov. 1997-fev. 1998., 1998. Disponível: <http://www.scielo.br/pdf/hcsm/v4n3/v4n3a06.pdf>. Acesso em: 13 de abr. 2016. 
OLIVEIRA, A. M. F. et al. (org.). O desafio da mobilidade urbana. Brasília: Câmara dos Deputados, Edições Câmara, 2015. Disponível em:

<http://bd.camara.leg.br/bd/handle/bdcamara/25220>. Acesso em: 11 de jan. 2017.

OPAS - ORGANIZACIÓN PANAMERICANA DE LA SALUD. Informe mundial sobre prevención de los traumatismos causados por el tránsito. Washington, 2004. Disponível em:

<http://iris.paho.org/xmlui/bitstream/handle/123456789/726/92\%2075\%2031599\%20X.pdf ?sequence=1>. Acesso em: 21 de abr. 2017.

PEREIRA, A. M. Cidade média e região: o significado de Montes Claros no norte de Minas Gerais, 2007. Tese de Doutorado, Uberlândia: Universidade Federal de Uberlândia, Instituto de Geografia, Geografia e Gestão do Território. Disponível em:

<http://www.ppgeo.ig.ufu.br/node/148>. Acesso em: 30 de jun. 2017.

PIACENTI, C. A.; FERRERA DE LIMA, J. (orgs.). Análise Regional: metodologia e indicadores. Curitiba (PR): Camões, 2012.

PINHEIRO, A. C.; FRISCHTAK, C. et. al. (org.). Mobilidade urbana: desafios e perspectivas para as cidades brasileiras. 1. ed. Rio de Janeiro: Elsevier/FGV/IBRE, 2015.

PREFEITURA MUNICIPAL DE TOLEDO. Toledo: Toledo em Números, Prefeitura do Município de Toledo, 2017. Disponível em: <http://www.toledo.pr.gov.br/portal/cidade-conhecatoledo/toledo-em-numeros>. Acesso em: 28 de mai. 2017.

RODRIGUES, J. M. Qual o estado da mobilidade urbana no Brasil? In: PAULA, M. de; BARTELT, D. D. (org.). Mobilidade urbana no Brasil: desafios e alternativas. Rio de Janeiro: Fundação Heinrich Böll, 2016. Disponível em:

<https://br.boell.org/sites/default/files/mobilidade_urbana_boll_brasil_web_.pdf>. Acesso em: 11 de jan. 2017.

RUSCHEL, A. C. O planejamento urbano e os acidentes de trânsito: um estudo sobre o município de Toledo-PR, 2016. Dissertação de Mestrado, Toledo: Universidade Estadual do Oeste do Paraná campus de Toledo, Pós-Graduação Stricto Sensu em Desenvolvimento Regional e Agronegócio.

SANTOS, M. Técnica, espaço, tempo: globalização e meio técnico-científico-informacional. 5. ed. São Paulo: Editora da Universidade de São Paulo, 2013.

SAULE JÚNIOR, N. O direito à cidade e a revisão da lei de parcelamento do solo urbano. In: SAULE JÚNIOR, N.; BRUNO, F. et. al. (org.). A perspectiva do direito à cidade e da reforma urbana na revisão da lei do parcelamento do solo. São Paulo: Instituto Pólis, 2008.

Disponível em: <http://www.polis.org.br/uploads/839/839.pdf>. Acesso em: 03 de jan. de 2017.

SILVA, A. A. Reforma urbana e o direito à cidade. SP: Pólis, 1991. Disponível em:< http://polis.org.br/publicacoes/reforma-urbana-e-o-direito-a-cidade/>. Acesso: 03/01/ 2017.

SILVA, A. L. da. Breve discussão sobre o conceito de cidade média. Geoingá, Maringá, v. 5, n. 1, p. 58-76, 2013. Doi: https://doi.org/10.4025/geoinga.v5i1.49203. Disponível em: 
<https://periodicos.uem.br/ojs/index.php/Geoinga/article/view/49203/751375140372>. Acesso: $12 / 7 / 2017$.

SOARES, B. R. Repensando as cidades médias brasileiras no contexto da globalização. Formação (Online), Presidente Prudente, UNESP, v. 1, n. 6, p. 55-63, 1999. Disponível em: <http://revista.fct.unesp.br/index.php/formacao/article/view/1167/1168>. Acesso em: 01 de dez. 2017.

SOARES, P. R. (2006). Cidades médias e aglomerações urbanas: a nova organização do espaço regional no sul do Brasil. In: SPÓSITO, E. S.; SPOSITO, M. E. B.; SOBARZO, O. (orgs). Cidades médias: produção do espaço. 1. ed. São Paulo: Expressão Popular.

SOUZA, E. R. de; MINAYO, M. C. de S.; MALAQUIAS, J. V. Violência no trânsito: expressão da violência social. In: BRASIL. Ministério da Saúde. Secretaria de Vigilância em Saúde. Impacto da violência na saúde dos brasileiros. Brasília: Ministério da Saúde, 2005. Disponível em:<http://bvsms.saude.gov.br/bvs/publicacoes/impacto_violencia.pdf >. Acesso em: $13 \mathrm{de}$ abr. 2016.

SPOSITO, M. E. B.; ELIAS, D.; SOARES, B. R.; MAIA, D. S.; GOMES, E. T. A. O estudo das cidades médias brasileiras: uma proposta metodológica. In: SPOSITO, M. E. B. (org.). Cidades médias: espaços em transição. 1. ed. São Paulo: Expressão Popular, 2007.

STAMM, C. O fenômeno dos movimentos pendulares dos trabalhadores intermunicipais entre cidades de porte médio: o caso de Cascavel e Toledo (PR). Dissertação (mestrado). Programa de Pós-graduação em Desenvolvimento Regional e Agronegócio. Universidade Estadual do Oeste do Paraná (Unioeste). 2005.

TORRES, S.; GINTERS, I. (org.). Cartilha reforma urbana já! São Paulo: Instituto Polis, 2016.

VASCONCELLOS, E. A. Políticas de transporte no Brasil: a construção da mobilidade excludente. Barueri, São Paulo: Manole, 2013.

WAISELFISZ, J. J. Mapa da violência 2013: acidentes de trânsito e motocicletas. Rio de Janeiro: CEBELA/Flacso, 2013. Disponível em:

<http://www.mapadaviolencia.org.br/pdf2013/mapa2013_transito.pdf>. Acesso em: 11 de jul. 2016. 